\title{
Indução, Confiabilidade e Predicados de Tipo Verdul
}

\author{
Luiz Helvécio MaRques SEgundo
}

\begin{abstract}
Collin Howson (2000) challenges van Cleve's reliabilist defense of induction (1984) based on an adaptation of Goodman Paradox (or new riddle of induction). I will try to show that Howson's argument does not succeed once it is self-defeating. Nevertheless, I point out another way which Howson could have employed the new riddle to undermine the reliabilist defense.
\end{abstract}

Keywords: Reliabilist defense of induction; Goodman Paradox; self-defeating.

Minha prática, dizeis vós, refuta as minhas dúvidas. Mas não compreendeis bem o propósito da minha pergunta. Como agente, estou plenamente convencido sobre esse ponto; mas como filósofo que tem o seu quinhão de curiosidade — não direi de ceticismo - quero conhecer o fundamento dessa inferência.

David Hume

\section{Introdução}

O desafio cético de Hume à indução é um daqueles típicos problemas filosóficos aparentemente intratáveis. Desde que apresentado pela primeira vez, principalmente em seu An Enquiry concerning Human Understanding (1748), muitos esforços foram dependidos na tentativa de solucioná-lo. E muita tinta foi gasta no exame de cada um deles. ${ }^{1}$ Mas nem tanta no que diz respeito à resposta confiabilista. ${ }^{2}$ Dentre os poucos filósofos que lhe de deram atenção está Colin Howson. Em seu Hume's Problem (2000) ele dedica um pequeno capítulo a fim de criticar a resposta confiabilista tal como defendida por James van Cleve em seu "Reliability, Justification, and the Problem of Induction" (1984). ${ }^{3}$ O objetivo deste artigo é tentar mostrar que o argumento de Howson contra o confiabilista não pode ser bem sucedido, uma vez que é autoderrotante.

Na seção 2 apresentarei brevemente o problema da indução. Na seção 3 apresento o argumento confiabilista a favor da indução. $\mathrm{O}$ argumento de Howson é então introduzido na seção 4. Argumento, na seção 5, que ele é autoderrotante. Na seção 6 , e última, aponto uma via de ataque da qual Howson poderia ter se valido.

Principia 19(1): 33-47 (2015).

Published by NEL — Epistemology and Logic Research Group, Federal University of Santa Catarina (UFSC), Brazil. 


\section{O desafio cético de Hume}

Eis um modo de se formular a desafio cético de Hume à indução (doravante, DC): ${ }^{4}$

1. Se a crença de $S$ de que $p$ é justificada indutivamente, então $S$ tem justificação para acreditar que a indução é um processo confiável de formação de crenças.

2. Mas $S$ não tem justificação para acreditar que a indução seja confiável.

3. Logo, a crença de $S$ de que $p$ não está justificada indutivamente.

A premissa 1 estabelece uma condição necessária para que um sujeito esteja indutivamente justificado em acreditar numa crença qualquer. À primeira vista é bastante plausível. Penso podermos derivá-la do Princípio de Justificação Inferencial (PJI) apresentado por Richard Fumerton (2006, p.39, p.100):

(PJI) A crença de que $p$ está inferencialmente justificada para $S$ sse (i) $S$ acredita que $p$ com base numa inferência apropriada, $I$, e (ii) $S$ acredita justificadamente que as premissas de $I$ tornam $p$ provável.

Se especificarmos em (i) que a inferência apropriada é uma inferência indutiva, e que em (ii) acreditar que as premissas dessa inferência aumentam a probabilidade de $p$ envolve uma crença de que a indução é um processo confiável, então temos a premissa (1) do argumento acima.

O seguinte sub-argumento pode ser oferecido a favor da premissa (2):

A) A crença de que a indução é confiável é justificada a priori ou a posteriori.

B) Não há maneira de justificá-la a priori.

C) Se $S$ tenta justificá-la indutivamente, acaba por raciocinar circularmente.

D) Mas um raciocínio circular não justifica o que for.

2) Portanto, $S$ não tem justificação para acreditar que a indução seja confiável.

(A) é indisputável. O raciocínio que estabelece (B) é simples: Justificar a indução dedutivamente depende de haver um princípio indutivo do tipo "Sempre que $x$ for observado tendo as propriedades $F_{1}, F_{2}, \ldots, F_{n}$, numa quantidade suficiente de vezes, todo $x$ (ou a maioria) terá $F_{1}, F_{2}, \ldots, F_{n}$ ". Tal princípio, contudo, não pode ser conhecido a priori (não é nem uma verdade lógica nem uma verdade conceitual), e por isso só pode ser introduzido a posteriori mediante razões indutivas. (C) é ainda mais claro: é patentemente circular tentar justificar a indução dizendo que na maioria das vezes a indução tem sido bem sucedida. (D) também parece óbvia. Por trás dela está algo como o seguinte pressuposto, CV: argumentos circulares são em geral epistemicamente viciosos - i.e. não conferem justificação. 
Se, portanto, não temos como sustentar a crença de que a indução é um processo confiável, as nossas crenças obtidas ou sustentadas com base no raciocínio indutivo não contam como justificadas. O resultado é devastador: uma vez que a maior parte das nossas crenças depende da indução para contarem como justificadas, ficamos na posição de que o nosso estoque de crenças justificadas é muito menor do que supúnhamos.

Do modo como acabamos de estabelecer o desafio cético, torna-se claro que premissas temos de atacar se quisermos evitá-lo. A estratégia que interessa a confiabilistas como van Cleve --e que nos interessa, portanto - é atacar (2). E para isso ele manterá que só podemos justificar a indução indutivamente. Ele irá, portanto, atacar CV. Se houver uma maneira de tornar plausível a ideia de que argumentos circulares conferem, em situações não triviais, justificação, poderemos abandonar a premissa (2) do desafio.

\section{A defesa confiabilista da indução}

A defesa confiabilista da indução de van Cleve não foi a primeira tentativa de solução indutiva ao problema da indução — Max Black (1958) e Richard Braithwaite (1953) já tinham tentado defender que a circularidade nem sempre é viciosa. Mas foi certamente a primeira a fornecer uma rejeição mais forte de CV. Ela depende de: (I) uma distinção entre tipos de circularidade, (II) estabelecer que um dos tipos não é epistemicamente vicioso, e (III) indicar que a o argumento indutivo a favor da indução é uma instância desse tipo.

(I) Circularidade quanto à premissa e quanto à regra.

Consideremos a seguinte definição de circularidade epistemicamente viciosa:

(CV) Um argumento $\Gamma$ é viciosamente circular sse:

(i) a sua conclusão, $c$, for uma repetição de uma das premissas de $\Gamma$, ou

(ii) $c$ for uma premissa de um sub-argumento $\Gamma$ ' a favor de pelo menos uma das premissas de $\Gamma$.

Considere agora dois sentidos diferentes de argumentos circulares: (a) circular quanto à premissa, e (b) circular quanto à regra. Um argumento é circular quanto à premissa se, e só se, a sua conclusão for explicitamente uma de suas premissas ou a sua conclusão estiver pressuposta em pelo menos uma das premissas. O caso mais claro é o de argumentos com a forma " $p$; $\log$ o $p$ ". Por outro lado, um argumento é circular quanto à regra se, e só se, a sua conclusão for acerca da fiabilidade do próprio argumento. Começamos com um conjunto de premissas $\left(P_{1}, \ldots, P_{n}\right)$, usamos uma regra $R$, e chegamos a uma conclusão acerca da confiabilidade de $R$. Ou seja, 
a verdade da conclusão - i.e. a forma inferencial ser confiável - é uma condição necessária para que a própria conclusão seja justificada. Por exemplo: Todos os argumentos dedutivos preservam a verdade. Este é um argumento dedutivo; logo, preserva a verdade.

(II) A circularidade quanto à regra não é viciosa

Note que a circularidade não é em si um problema. O problema é o vício epistêmico. Se a minha crença de que $p$, por exemplo, depender de um argumento para a sua justificação, e as premissas desse argumento dependerem de alguma forma que a minha crença de que $p$ esteja justificada, a despeito de ter fornecido um argumento, não terei justificado a minha crença de que $p$. Se permitíssemos tal movimento, então poderíamos justificar qualquer crença mediante a um argumento circular quanto à premissa: essa é a fonte do vício epistêmico, a justificação seria uma questão muito fácil. van Cleve (1984, p.558) pensa que na maior parte dos casos (se não em todos) de vício epistêmico estão envolvidos argumentos circulares quanto à premissa. Pelo menos, até agora, $\mathrm{CV}$ parece deixar de fora os argumentos circulares quanto à regra. Na verdade, van Cleve faz as coisas de modo que a definição de CV e a de argumentos circulares quanto à premissa coincidam.

Mas o que garante de fato que uma terceira condição, como a seguinte, também não faça parte de CV?

(iii) a conclusão de $c$ for acerca da própria confiabilidade da regra $R$ cujo argumento $\Gamma$ é uma instância.

Ou seja, o que nos garante que a circularidade quanto à regra também não seja um caso de circularidade viciosa? Num contexto em que está em jogo a confiabilidade de uma regra $R$, cujo argumento $\Gamma$ é uma instância, oferecer $\Gamma$ como um argumento a favor da confiabilidade de $R$ é claramente viciosamente circular. De modo que a condição (iii) teria de fazer parte de CV.

Para impedir, então, que (iii) faça parte de CV van Cleve recorre à defesa do confiabilismo processual de Alvin Goldman (1979). De acordo com o confiabilismo processual, grosso modo, uma crença é justificada sse for produzida por um processo confiável de formação de crenças. Onde a confiabilidade é a tendência que um processo tem de produzir mais crenças verdadeiras do que falsas. Explicitamente:

(CP) A crença de $S$ de que $p$ é justificada sse (a) for produzida por um processo incondicionalmente confiável, ou (b) for produzida por um processo condicionalmente confiável e suas crenças de input forem justificadas.

Onde um processo incondicionalmente confiável é um processo independente de crenças (e.g. a percepção) e um processo condicionalmente confiável é um processo 
dependente de crenças cuja justificação das crenças de output depende das crenças de input estarem justificadas.

A condição (b) supostamente dá conta da justificação inferencial. Note que CP não impõe qualquer condição que diga respeito à formação de crenças sobre a confiabilidade do processo; para que uma crença seja justificada basta que tenha sido produzida de maneira confiável. Assim, quando $S$ raciocina de acordo com $R$, se $R$ for uma regra confiável, ainda que a conclusão de $S$ seja sobre a própria confiabilidade de $R$, tal crença será justificada.

(III) $\mathrm{O}$ argumento indutivo a favor da indução não é viciosamente circular

Levemos agora em conta agora o seguinte argumento indutivo a favor da confiabilidade da indução, chamemos-lhe A:

1. Até agora grande parte dos nossos argumentos indutivos (adequadamente traçados) com premissas verdadeiras tiveram também conclusão verdadeira.

2. Logo a maior parte dos argumentos indutivos (adequadamente traçados) com premissas verdadeiras terá conclusão verdadeira.

Dado que a confiabilidade é a tendência de um processo em produzir mais crenças verdadeiras do que falsas, o argumento A parece suficiente para justificar a crença de que a indução é um processo fiável - claro, contando que a indução seja de fato confiável.

Se prestarmos atenção, A não é circular quanto à premissa, apenas circular quanto à regra. $\mathrm{E}$ à luz da interpretação confiabilista de CV, não é viciosamente circular. Assim, os confiabilistas parecem ter um argumento para rejeitar a premissa (2) de DC.

Antes de passar ao argumento de Howson, deixe-me mencionar rapidamente uma dificuldade a que van Cleve e outros confiabilistas enfrentarão para rejeitar (2). A premissa (1) de DC exige que tenhamos uma crença sobre a confiabilidade da indução a fim estarmos indutivamente justificados que $p$, como a condição (ii) de PJI deixa claro. A defesa confiabilista de van Cleve (e seus simpatizantes) mantém (1) e rejeita (2). Ora, mas como vimos acima, para defender que a circularidade quanto à regra não é viciosa, os confiabilistas rejeitam que precisamos formar crenças sobre a confiabilidade da regra inferencial. Parece, portanto, que a razão para rejeitar (2) é também uma razão para rejeitar (1). Mas isso nos deixaria com o seguinte resultado. Da negação de (2) obtemos que $S$ está justificado a acreditar que a indução é confiável. Da negação de (1) obtemos que $A$ crença de $S$ de que p está indutivamente justificada $\& \neg$ (S está justificado em acreditar que a indução é confiável). Ora, isso nos deixa com uma contradição explícita: $S$ está justificado a acreditar que a indução é confiável \& $\neg(S$ está justificado a acreditar que a indução é confiável). van Cleve, portanto, não poderia aceitar o desafio cético e ainda assim manter a sua posição. Penso que tal 
dificuldade pode ser evitada se restringirmos a justificação exigida na conseqüente de (1) à justificação proposicional (ao invés da doxástica).

Seja como for, deixemos de lado a potencial dificuldade acima, e aceitemos, por amor à argumentação, que a estratégia de resposta de van Cleve é plausível — como de fato o é à primeira vista.

\section{Howson e os predicados do tipo verdul}

Se o confiabilista estiver correto, então o argumento A é suficiente para justificar a nossa crença de que a indução é confiável. Podemos, contudo, utilizar as considerações de Nelson Goodman $(1946 ; 1954)$ acerca da confirmação de hipóteses conhecidas como o paradoxo de Goodman ou o novo enigma da indução - mais o argumento A para atingir a conclusão de que a indução é infiável. Essa estratégia é adotada por Colin Howson (2000). O argumento contra o confiabilista, chamemo-lo DG, será o seguinte:

1) Se $S$ está justificado a raciocinar indutivamente, então a indução é confiável. (confiabilismo)

2) Mas a indução é infíável. (confiabilismo; paradoxo de Goodman)

3) Logo $S$ não está justificado a racionar indutivamente.

O propósito desta seção é mostrar como o paradoxo de Goodman poderia fornecer bases, de acordo com Howson, para pensarmos que a premissa (2) de DG é verdadeira.

Considere a seguinte previsão indutiva comum:

(PI)

(1) Todas as esmeraldas observadas até agora foram verdes.

(2) Logo a próxima esmeralda a ser observada será verde.

Considere então o seguinte predicado:

$$
\text { “... é verdul". }
$$

Um objeto é verdul sse (i) for observado antes de 2100 e for verde ou (ii) for observado depois de 2100 e for azul.

Note que os predicados “... é verde" e “... é verdul” são formalmente equivalentes, i.e., sintaticamente um pode ser definido em termos do outro. Podemos definir “... é verde" de maneira análoga a como definimos “... é verdul": $x$ é verde sse tiver sido observado antes de 2100 e for verdul, ou for observado depois de 2100 e for azerde, 
sendo o predicado “... é azerde" definido como um objeto observado antes de 2100 e azul ou observado depois de 2100 e verde.

Da definição de verdul mais a constatação de que todas as esmeraldas observadas até agora foram verdes, segue-se que todas as esmeraldas observadas até agora são verduis.

Levemos em conta agora uma outra previsão indutiva nada comum:

\section{$\left(\mathbf{P I}{ }^{*}\right)$}

(1) Todas as esmeraldas observadas até agora foram verduis.

(2) Logo, a próxima esmeralda a ser observada será verdul.

Atentemo-nos, então, para as consequências disso. Supondo que as nossas práticas indutivas sejam bem sucedidas, PI e PI* preverão exatamente a mesma observação até 2100. Por exemplo, dois estudiosos de esmeraldas, um usando PI e o outro PI*, concordarão naquilo que esperavam observar. Pense agora naquilo que aconteceria depois de 2100. De acordo com PI, a primeira esmeralda a ser observada depois de 2100 será verde. Mas de acordo com PI*, a primeira esmeralda a ser observada depois de 2100 será azul. Isso porque se um objeto é verdul, presumivelmente ele é verde e foi observado antes de 2100. Mas estamos falando de um objeto que será observado depois de 2100, de modo que ainda que seja verde, não será verdul (lembrese que a satisfação da condição (i) requer a satisfação de uma conjunção). Mas se a previsão é de que a primeira esmeralda a ser observada depois de 2100 será verdul, só nos resta a condição (ii), de modo que ela terá de ser azul (a satisfação de (ii) também depende da satisfação de uma conjunção - ser azul e observado depois de 2100). Contudo, se uma esmeralda possuir ambas as propriedades - a de ser verde e a de ser verdul - ao fazermos uma generalização indutiva terminaremos com a conclusão absurda de que a primeira esmeralda a ser observada depois de 2100 será verde e não-verde ao mesmo tempo. ${ }^{5}$

Esse caso do verdul mostra que a regra indutiva que nos permite fazer previsões massivamente falsas a partir de premissas verdadeiras. E não só as previsões. Também a regra da generalização indutiva fica comprometida, uma vez que seríamos levados de premissas verdadeiras - a esmeralda 1 é verde; a esmeralda ${ }_{2}$ é verde, a esmeralda é verde (e, por isso, todas verduis) - a uma conclusão falsa — todas as esmeraldas depois de 2100 são azuis. Ora, de acordo com a nossa definição de fiabilidade — a tendência de um processo ou método em produzir mais crenças verdadeiras do que falsas - as nossas induções seriam infiáveis. Nesse caso parece já que o confiabilista formaria a crença de que a indução é infiável.

Howson (2000, p.30-1), contudo, prefere a seguinte adaptação do caso verdul para mostrar que o argumento A, se sustenta a conclusão de que a indução é confiável, 
pode também sustentar a conclusão de que a indução é infiável. Considere primeiro os seguintes predicados:

“... é correto".

Uma inferência é correta sse tem conclusão verdadeira.

$$
\text { “... é errado". }
$$

Uma inferência é errada sse tem conclusão falsa.

Considere agora a premissa do argumento A — grande parte das inferências indutivas traçadas até agora tiveram conclusão verdadeira. Dada a definição de inferência correta, segue-se que essas inferências indutivas com conclusão verdadeira são também corretas. Assim, dada a premissa de A, segue-se que grande parte das inferências indutivas traçadas até agora são corretas. Considere então outro predicado nada usual:

$$
\text { “... é cerrado". } 6
$$

Uma inferência é cerrada sse (i) tiver sido traçada até agora e for correta ou (ii) ainda não tiver sido traçada e for errada.

Ficamos então com o seguinte argumento:

\section{Argumento A*}

(1) Grande parte das inferências indutivas até agora foram cerradas.

(2) Logo, a maioria das inferências indutivas é cerrada.

A premissa (1) é verdadeira dada a definição de inferência cerrada mais a definição de inferência correta. Ou seja, uma vez que grande parte das inferências indutivas traçadas até agora tiveram conclusões verdadeiras, essas inferências são também corretas e, por conseguinte, são também inferências cerradas. Dada a regra de generalização indutiva - a mesma regra usada no argumento $\mathbf{A}$ - podemos inferir (2) a partir de (1). Seguindo os confiabilistas, se a indução é confiável, então estamos justificados em acreditar em (2).

Mas agora aparece um problema. Vejamos o que está em jogo na conclusão de A*. Ela diz que a maioria das inferências indutivas é cerrada. Ou seja, ou (i) já foi traçada e tem conclusão verdadeira, ou (ii) ainda está por traçar e tem conclusão falsa. Como no caso verdul, as inferências que estão por traçar, ainda que tenham conclusões verdadeiras, não contarão como inferências cerradas. Assim, só nos resta (ii), isto é, a conclusão de que a maioria das inferências indutivas tem conclusão falsa. O que por sua vez implica que a indução é infiável. Mas se é assim, o confiabilista tem agora uma crença justificada na infiabilidade da indução. E como já mencionado, possui um revogador para qualquer crença indutiva.

Principia 19(1): 33-47 (2015). 


\section{Autoderrota}

Howson pensa que essa objeção "mostra dramaticamente a frivolidade da justificação circular, seja ela circular quanto à regra ou não" (p.31). E a razão é óbvia: ainda que o uso de uma indução nos forneça a mínima garantia epistêmica de que a indução seja confiável, ela também nos fornece a garantia de que a indução é infiável. Todavia, algo passou despercebido aos olhos de Howson. E é bastante simples: o argumento A* não pode fornecer qualquer garantia ou razão para considerar a indução infiável porque simplesmente é autoderrotante. Se a sua conclusão for verdadeira, as premissas (ainda que verdadeiras) deixarão de fornecer suporte epistêmico a essa mesma conclusão.

Um argumento $\Gamma$ é autoderrotante sse a justificação que $S$ tem para acreditar em sua conclusão, $c$, implicar (i) na revogação ${ }^{7}$ da justificação que $S$ tem para acreditar em suas premissas, ou (ii) implicar na crença de que a forma de $\Gamma$ é infiável. $\mathrm{O}$ argumento de Howson, mostrarei, satisfaz (ii).

Vejamos. Aceitemos, para fins de argumentação, que a constatação de que todos os argumentos indutivos apropriadamente traçados anteriores a 2100 tiveram conclusão verdadeiras confirma a hipótese de que todos os argumentos indutivos são cerrados. Uma vez que confirma, somos levados à conclusão indutiva de que a indução é infiável. Mas se a indução é infiável, dado o confiabilistmo, segue-se que os argumentos indutivos não transmitem justificação, ou pelo menos temos um revogador para a suposição de que transmitem. Ora, se os argumentos indutivos não transmitem justificação, então a conclusão de $A^{*}$ não tem qualquer apoio epistêmico. Por outro lado, se temos um revogador para a suposição de que os argumentos indutivos transmitem justificação, não podemos (sob pena de irracionalidade) usar um argumento indutivo para o que quer que seja e, por conseguinte, para sustentar que a indução é infiável. De qualquer modo, Howson não consegue sustentar a conclusão pretendida.

Uma resposta do lado de Howson poderia ser a seguinte. A conclusão de A* estabelece que apenas que as induções de primeira ordem são infiáveis, deixando intocadas as induções de segunda ordem (ou ordens superiores). O argumento A* poderia, então, ser reescrito assim:

\section{Argumento $A^{* \prime}$}

(1) Grande parte das inferências indutivas de primeira ordem traçadas até agora foram cerradas.

(2) Logo, a maioria das inferências indutivas de primeira ordem é cerrada.

Como o argumento $\mathbf{A}^{* \prime}$ é uma indução de segunda ordem, i.e., uma indução acerca de induções, a sua conclusão parece não suspender a apoio que a premissa 
fornece à conclusão. Note que a conclusão diz que apenas as induções de primeira ordem é que são cerradas.

Ora, mas o argumento A é também uma inferência de segunda ordem; logo, de acordo com a presente resposta, é também capaz de fornecer apoio à conclusão de que as induções de primeira ordem são confiáveis. Mas isso não é suficiente para anularmos $\mathbf{A}^{* \prime}$. E a razão é que a premissa (1) de $\mathbf{A}$ é equivalente à premissa de $\mathbf{A}^{* \prime}$.

Essa manobra, porém, é enganadora. Ela parece pressupor que $\mathbf{A}$ e $\mathbf{A}^{* \prime}$ instanciam tipos diferentes, pois se $\mathbf{A}^{* \prime}$ for do mesmo tipo que $\mathbf{A}$, uma vez que $\mathbf{A}^{* \prime}$ estabelece a infiabilidade de toda e qualquer indução de primeira ordem, $\mathbf{A}^{* \prime}$ se autoderrotaria. Mas dizer que $\mathbf{A}$ e $\mathbf{A}^{* \prime}$ são de tipos diferentes implica que eles têm formas lógicas diferentes. Muito embora A e $\mathbf{A}^{* \prime}$ sejam de ordens diferentes, elas têm a mesma forma lógica. Uma analogia pode nos ajudar. Pense nos seguintes modus ponens:

$\mathrm{MP}_{1}$

1) Se Sancho é mexicano, então gosta de nachos.

2) Sancho é mexicano.

3) Logo, Sancho gosta de nachos.

$\mathrm{MP}_{2}$

1) Se $\mathrm{MP}_{1}$ tem premissas verdadeiras, então sua conclusão tem de ser verdadeira.

2) $\mathrm{MP}_{1}$ tem premissas verdadeiras.

3) Logo, $\mathrm{MP}_{1}$ tem conclusão verdadeira.

$\mathrm{O}$ fato de $\mathrm{MP}_{1}$ e $\mathrm{MP}_{2}$ serem argumentos de ordem diferente, daí não segue que tenham forma diferente. E se não têm formas diferentes, não podem ser de tipos diferentes. Se assim é, por que, afinal de contas, teríamos alguma razão para pensar que o mesmo não vale para os argumentos $\mathbf{A}$ e $\mathbf{A}^{* \prime}$ ? Nenhuma. Logo, $\mathbf{A}$ e $\mathbf{A}^{* \prime}$ não são de tipos diferentes. $E$ se não são de tipos diferentes, segue-se que $\mathbf{A}^{* \prime}$ é autoderrotante.

$\mathrm{O}$ que torna ainda mais claro que $\mathbf{A}$ e $\mathbf{A}^{* \prime}$ são da mesma forma é que a única coisa diferente em ambos é que a ocorrência de "tiveram conclusão verdadeira" em A foi substituída por "é cerrada". É como substituir "mexicano" por "pessoa nascida no México" em $\mathrm{MP}_{1}$.

Outra razão pela qual $\mathrm{A}^{* \prime}$ não funciona é que teríamos de sustentar a sua confiabilidade de algum modo. Afinal, se o contexto aqui é responder ao cético, de nada adiantaria simplesmente assumir a confiabilidade das induções de segunda ordem. De que modo isso poderia ser feito? Recorrendo-se a uma indução de terceira ordem que diz que todos os argumentos de segunda ordem com premissas verdadeiras e apropriadamente traçados tiveram até agora conclusão verdadeira e, que, portanto, as induções de segunda ordem são confiáveis? Isso claramente não pode ser, uma vez 
que poderíamos construir agora uma nova indução problemática, $\mathbf{A}^{* \prime \prime}$, que conclua que todas as induções de segunda ordem bem sucedidas são cerradas, e, portanto, que terão conclusões falsas depois de 2100 . Assim, um potencial defensor de Howson é novamente incapaz de estabelecer a conclusão de $\mathrm{A}^{* \prime}$.

E seria inútil também se esse defensor tentasse captar qualquer regularidade acerca da falha das induções de primeira ordem. Uma vez que o argumento $A^{* \prime}$ é um argumento do tipo verdul, ele depende, assim como o argumento original de Goodman, da suposição que o predicado “... é cerrado" não é projetável, i.e., não projeta regularidades para o futuro. Novamente, a defesa de $\mathrm{A}^{* \prime}$ falha.

Uma outra tentativa de se evitar a autoderrota, argumentaria o proponente de A*, seria dizer que a sua conclusão não se aplica a si mesmo. Ela diz que os argumentos indutivos futuros serão infiáveis, não que os do passado o são. Mas isso é compreender mal o conceito de confiabilidade. Um processo é confiável se tende a produzir mais crenças verdadeiras do que falsas; e infiável se tende a produzir mais crenças falsas do que verdadeiras. De acordo com a conclusão de A*, como as induções a serem traçadas terão conclusão falsa, a indução tenderá a produzir mais crenças falsas do que verdadeiras, não importando se até agora ela tem produzido uma razão alta de crenças verdadeiras. O proponente de $\mathbf{A}^{*}$, ao argumentar assim, é como alguém que compra um relógio vagabundo, daqueles que depois alguns meses de uso passa a se atrasar com frequência, mas o destrói ante disso e nos diz que o relógio é confiável porque até aquele momento tinha marcado as horas corretamente, sem se atrasar.

Sendo assim, o ataque ao confiabilista através do argumento A* é mal sucedido e, portanto, não fornece qualquer revogador ao confiabilista.

\section{Uma via mais modesta}

A despeito da falha do argumento acima, Howson poderia ser mais modesto. Ao invés de usar o argumento A* que é autoderrotante, ele poderia simplesmente usar o argumento original de Goodman — como já aludido na seção III — a fim de sustentar a premissa (2) de DG. Na verdade, o próprio Howson parece sugerir tal coisa, embora não o tenha feito por achar que seu argumento $A^{*}$ fosse decisivo. Nas suas próprias palavras (p.30):

[...] Uma regra indutiva que nos diz que após observar um amplo número de A's podemos inferir [...] que o próximo objeto observado será um A, ou que os objetos futuros na classe de referência serão A's, claramente nos diz (i) que após observar esmeraldas verdes o suficiente podemos inferir que a próxima esmeralda a ser observada será verde, e (ii) que podemos inferir que a próxima esmeralda será verdul. Em outras palavras, a regra nos diz que a próxima esmeralda observada será tanto verde quanto azul. Extrapolar o

Principia 19(1): 33-47 (2015). 
comportamento passado é, portanto, não apenas um procedimento infiável: é maximamente infiável.

Ora, se Howson foi capaz de chegar à conclusão de que a indução é maximamente infiável simplesmente pelo paradoxo de Goodman, o argumento $\mathbf{A}^{*}$ não precisaria ser oferecido. Na verdade, como é um argumento autoderrotante, sequer poderia ser oferecido.

Poder-se-ia objetar, contudo, que essa estratégia mais modesta também esta fadada ao fracasso, uma vez que é também um argumento indutivo e não consegue escapar das mesmas objeções feitas a $\mathbf{A}^{*}$. A ideia do opositor é que o partidário de Howson teria de argumentar mais ou menos assim:

\section{Argumento A**}

(1) Várias previsões indutivas sustentam que um objeto o depois do tempo $t$ terá as propriedades incompatíveis $F$ e $G$ (onde $G$ implica $\neg F$ ).

(2) Logo, a maioria das previsões indutivas concluirá que $o$ depois de $t$ terá $F$ e $G$.

Como (2) afirma que a maioria das conclusões indutivas será absurda, segue-se, dada a definição de confiabilidade, que a indução é infiável. A** seria uma espécie de metaindução pessimista. Mas como é um argumento do mesmo tipo, extrapolação do observado ao inobservado, sofre dos mesmos problemas de A* e é, portanto, autoderrotante.

O objetor se equivoca, porém. Neste caso o argumento é completamente a priori e envolve apenas (i) a compreensão do que está em jogo na aplicação de regras inferenciais e (ii) a suposição de que os predicados do tipo “... é verde" e “... é verdul" são equivalentes. Com isso o argumento pode ser gerado. No que diz respeito a (i), a compreensão exigida é a de que a regra indutiva permite que passemos de uma premissa (ou premissas) sobre algo já observado a uma conclusão sobre algo inobservado. Certamente que a justificação (em termos de provas metateóricas) de uma regra indutiva terá de ser em alguma medida a posteriori, uma vez que provas de completude e correção não estão disponíveis para qualquer sistema de lógica indutiva. Mas o que está em jogo aqui não é o fornecimento de tais provas, é algo mais fundamental. É a compreensão do que está por trás da aplicação de regras, e isso é a priori. A ideia é que uma regra de inferência permite a um sujeito passar de um conjunto de proposições a outro. E dados os nossos propósitos epistêmicos de perseguir a verdade, a ideia é que temos de adotar aquelas regras que nos permita passar de proposições verdadeiras a outras proposições verdadeiras. Se a regra preserva ou não a verdade é outro assunto.

Talvez não tenha ficado completamente claro em que sentido a compreensão do que está por trás da aplicação de regras é a priori. Não estou dizendo que não po- 
demos aprender a posteriori uma regra; na verdade, a maioria das regras que aprendemos nos é fornecida por alguém ou por algum manual e, portanto, a posteriori. O que estou dizendo é que logo que começamos a pensar sobre regras, sobre o que está envolvido nas suas aplicações, descobrimos algo bastante geral: siga tal e tal procedimento para obter tal e tal resultado. E, embora tal conclusão possa ser atingida através da constatação empírica de várias regras em vigor, ela é justificável a priori. A seguinte experiência mental nos ajuda a ver por quê. Suponha uma comunidade destituída de quaisquer regras (morais, políticas, intelectuais, etc.). Ainda assim é concebível que os habitantes dessa comunidade fossem capazes de entender o que é uma regra e, por conseguinte, como aplicá-la, o que seria uma violação de tal regra, etc. Além do mais, não há qualquer experiência possível que refute a definição de regra.

Uma vez estabelecido (i), basta pensarmos nas conseqüências de uma inferência indutiva em que se faça uso do predicado “... é verdul”. Dado que “... é verdul” é logicamente equivalente a "... é verde", o que também sabemos a priori, (ii) é também estabelecido. $\mathrm{O}$ argumento então seria:

1. Se uma regra de inferência é confiável, então ela tende a preservar a verdade. (Def.)

2. A aplicação de regras indutivas nos leva a resultados inconsistentes. (Parad. Goodman)

3. Se uma regra leva a resultados inconsistentes, então é infiável. (Def.)

4. Logo, as regras indutivas são infiáves.

As premissas (1) e (3) são incontestáveis. Embora (2) possa não parecer tão convincente, é esse o resultado do paradoxo de Goodman. E o mais importante, nenhuma dessas premissas foi estabelecida indutivamente. Assim, somos capazes de fornecer um argumento cujas premissas o confiabilista tem de aceitar. Por conseguinte, o confiabilista tem agora um revogador que refuta a sua crença de que a indução é confiável.

\section{Conclusão}

Vimos que o ataque original de Howson à defesa confiabilista da indução a partir da adaptação do paradoxo do verdul falha, pois é autoderrotante. Não obstante, o próprio paradoxo do verdul constitui uma dificuldade real à defesa confiabilista, pois, junto de outras suposições, empurra o confiabilista para a conclusão de que não estamos justificados em acreditar que a indução seja um processo confiável — ou seja, a premissa (2) de DC.

van Cleve, em seu artigo, simplesmente supõe que "temos uma resposta parcial ao 'novo enigma' [da indução]” (p.556). Infelizmente ele sequer dá pistas de qual. 
Mas o que nos fica claro aqui é que tal resposta não deveria apelar para a própria indução. Tanto melhor para o confiabilista será se o paradoxo do verdul puder ser resolvido independentemente.

\section{Referências}

Black, M. 1958. Self-Supporting Inductive Arguments. The Journal of Philosophy 55(17): 71825.

Braithwaite, R. 1953. Scientific Explanation. Cambridge University Press.

Fumerton, R. 2006. Epistemology. Blackwell Publishing.

Gabbay, D. M. et al. 2011. Handbook of the History of Logic. Volume 10: Inductive Logic. Elsevier.

Goldman, A. 1979. What is a Justified Belief?. In: G. Pappas (ed.) Justification and Knowledge.

Reidel.

- 1986. Epistemology and Cognition. Harvad Universtity Press.

Goodman, N. 1946. A Query on Confirmation. The Journal of Philosophy 43(14): 383-5.

- 1954. Fact, Fiction and Forecast. Indianapolis: Bobs-Merrill.

Greco, J. 2000. Putting Skeptics in their Place: The Nature of Skeptical Arguments and its Role in Philosophical Inquiry. Cambridge University Press.

Howson, C. 2000. Hume's Problem: Induction and Justification of Belief. Oxford University Press.

Hume, D. 1748. An Enquiry concerning Human Understanding. Edição, introdução e notas de Peter Millican (2007). Oxford University Press.

Lange, M. 2011. Hume and the Problem of Induction. In: D. Gabbay et. al. (2011).

Lipton, P. 2000. Tracking Track Records. Proceedings of Aristotelian Society LXXIV: 179-206.

Papineau, D. 1992. Reliabilism, Induction, and Scepticism. The Philosophical Quarterly 42 (166): 1-20.

- 1994. Philosophical Naturalism. Blackwell.

Pollock, J. 2008. Defeasible Reasoning. In: J. Adler; L. Rips (eds.) Reasoning: Studies in Human Inference and its Foundations. Cambridge University Press.

Psillos, S. 1999. Scientific Realism: How Science Tracks Truth. Cambridge University Press.

Rhoda, A. R. 2003. The Problem of Induction: An epistemological and methodological response. Tese de doutorado, Fordham University.

Sankey, H. 2008. Scientific Realism and The Rationality of Science. Ashgate.

Tucker, C. 2009. Evidential Support, Reliability, and Hume's Problem of Induction. Pacific Philosophical Quarterly 90: 503-19.

van Cleve, J. 1984. Reliability, Justification, and the Problem of Induction. P. Frencn; T. Uehling; H. Wettstein (eds.) Midwest Studies in Philosophy IX: 555-67.

Weintraub, R. 2008. Scepticism about Induction. In: J. Greco (ed.) The Oxford Hanbook of Skepticism.

Luiz Helvécio Marques Segundo Doutorando em Filosofia pela UFSC. luizhelveciosegundo@gmail.com

Principia 19(1): 33-47 (2015). 


\section{Notas}

${ }^{1}$ Para exposições sucintas das principais abordagens ao problema da indução veja Weintraub (2008) e Lange (2011). Os artigos em Gabbay, Hartmann \& Woods (2011), do qual o artigo do próprio Marc Lange faz parte, ilustram bem o interesse dos filósofos pela indução.

2 Para alguns filósofos que se interessaram pela defesa confiabilista, cf. Greco (2000), Levin (1993), Lipton (2000), Rhoda (2003), Sankey (2008), Tucker (2009).

${ }^{3}$ David Papineau $(1992,1994)$ e Stathis Psillos (1999) subscrevem a defesa de van Cleve, embora não avancem qualquer novidade. Alvin Goldman (1986) menciona de passagem, numa nota de rodapé (p.394), tal defesa e também a subscreve.

${ }^{4}$ Meu objetivo aqui não é exegético, de modo que não me comprometo com qualquer interpretação controversa do argumento de Hume. É suficiente para os meus propósitos que Hume tenha apresentado o desafio cético em seus escritos, ainda que não o tenha endossado. Assim, o meu uso de "desafio cético de Hume" não me compromete com uma interpretação cética de Hume.

${ }^{5}$ Goodman já tinha apresentado o paradoxo em 1946 em seu "A Query on Confirmation". Lá, o seu exemplo é um tanto mais intuitivo do que o do verdul. Considere uma urna com 100 bolas vermelhas. Foram retiradas 99 bolas e constatado que eram vermelhas. Assim, pode-se fazer a previsão de que a centésima bola será vermelha. Mas imagine que o predicado $R$, “... é vermelho e foi observado antes do tempo $t$, ou é não-vermelho e foi observado depois de $t$ ", é introduzido. E imagine também que todas as 99 bolas foram observadas antes de $t$. Assim, é verdade que as 99 bolas são $R$. E isso nos levará à previsão de que tal bola será não-vermelha, o que claramente entra em conflito com a nossa primeira previsão de que a bola seria vermelha. Como o exemplo do verdul se tornou canônico na bibliografia, preferi usá-lo.

${ }^{6}$ Howson usa o termo "ring", uma junção de "right" e "wrong", assim como Goodman fez com "grue", uma junção de "green" e "blue". "Cerrado", a nossa tradução de "ring", é, então, a junção de "certo" e "errado".

7 Estou usando "revogação" aqui no sentido de John Pollock (2008). Há dois casos em que uma crença de que $p$ pode ser revogada - i.e. ter sua justificação suspensa: no caso de $S$ ter uma crença justificada de que não- $p$ (ou um conjunto de crenças justificadas que implique não- $p$ ), ou $S$ tenha crenças justificadas que enfraqueçam o apoio evidencial que $S$ tem para $p$.

Principia 19(1): 33-47 (2015). 